\title{
Educación y pandemia
}

\author{
Dr. Ignacio Arzac Ulla
}

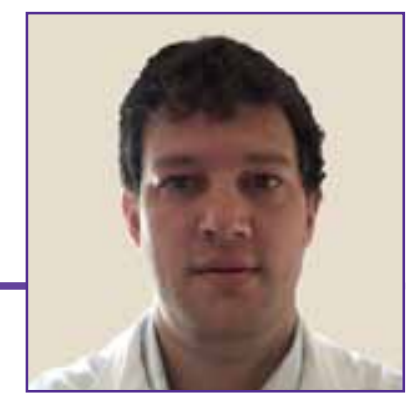

Estimados colegas:

Estamos atravesando uno de los momentos más complejos que nos toca vivir como médicos y personas. Desde que se desató este mal llamado coronavirus, nos fuimos adaptando y pusimos todos nuestros esfuerzos para sacarle algo de beneficio a esta situación diferente que estamos atravesando. Afortunadamente disponemos de una gran variedad de plataformas virtuales para la formación académica, como los webinars, congresos online, ateneos, charlas y distintas formas de educación y actualización continuas. En la mayoría de los casos, son conferencias gratuitas y a solo un clic de distancia.

Lo más interesante de estas formas de actualización y educación es que los que vivimos y trabajamos fuera de Buenos Aires y el AMBA podemos tener un contacto más cercano con la traumatología, permanecer actualizados y participar activa o pasivamente de ellos.

Hace tiempo que nuestra revista viene trabajando sobre estas bases para hacer que el conocimiento científico llegue a todos de igual forma, facilitando, cada vez más, su acceso. A partir de 2018, se puede acceder a todas las revistas de la Asociación Argentina de Ortopedia y Traumatología mediante una aplicación en los teléfonos móviles. Allí se pueden consultar las ediciones anteriores, la actual, los artículos más leídos y los próximos trabajos que se publicarán.

La Revista de la Asociación es el órgano oficial de publicaciones de nuestra entidad. Está indexada en LILACS (Literatura Latinoamericana en Ciencias de la Salud), REDIB (Red Iberoamericana de Innovación y Conocimiento Científico), DOAJ (Directory of Open Access Journals), JournalTOCs, Dialnet y, a partir de 2011, se encuentra "en línea" en SCIELO (Scientific Electronic Library Online). También adhiere al Código de Ética del Committee of Publication Ethics (COPE) y del Council of Science Editors (CSE), se identifica con el DOI (Digital Object Identifier) CROSSREF y se encuentra en el catálogo de revistas científicas de la Harvard Library, de Sheffield Hallam University-Library Gateway. También podrán encontrarla a través de WorldCat y AmeliCA.

La tarea de disponer de una revista de esta magnitud científica no es sencilla, se necesita de un equipo de trabajo muy grande, que deja muchas horas en mejorar edición tras edición nuestra revista. Invito a todos a participar activamente, publicando trabajos de investigación, colaborando como revisores de los artículos o simplemente consultándola ante inquietudes. 